\title{
Evaluation on Ecological Civilization Construction Level in Guizhou Based on Intuitionistic Fuzzy Analytic Hierarchy Process
}

\author{
Xinpu Wang, ${ }^{1, *}$ Mu Zang ${ }^{2, \dagger}$ \\ 1. College of Big Data Application and Economics, Guizhou University of Finance and Economics \\ Huaxi Guiyang Guizhou, China \\ 2. College of Big Data Application and Economics, Guizhou University of Finance and Economics \\ Huaxi Guiyang Guizhou, China
}

Received January 7, 2019

Accepted March 4, 2019

\begin{abstract}
In order to better build the ecological environment of Guizhou province, accelerate the marketization and capitalization of Guizhou province's ecological resources, and evaluate and study the construction level of Guizhou's ecological civilization. This paper, by using IFAHP, the establishment of intuitionistic fuzzy judgment matrix, consistency test, calculate the nine-province each secondary index to the weight of a layer and target layer, the comprehensive evaluation value is calculated and sorted. The empirical research shows that the ecological civilization construction level of Guizhou province is relatively high, but the level distribution of all prefectures and cities is very uneven, and the difference between the highest score southeast Guizhou and the lowest score Liupanshui is 4.87 . Therefore, it is necessary to accelerate the construction of ecological civilization in various prefectures and cities, so as to improve the construction level of ecological civilization in the whole province and promote regional economic development.
\end{abstract}

Keywords: construction of ecological civilization; the level of ecological civilization construction; IFAHP; comprehensive evaluation

\section{Introduction}

At the Fifth Plenary Session of the Eighteenth Central Committee of the Communist Party of China, the development concept of "innovation, coordination, green, open and sharing" was put forward, which put forward higher requirements for the construction of ecological civilization. The construction of ecological civilization is of great significance to solve the resource and environment problems facing our country. "Green water and green hills are Jinshan and Yinshan". Green development has become the theme of China's economic and social development in the 13th Five-Year Plan period and even in the longer term. The key to building a resource-saving and environment-friendly society lies in the improvement of ecological environment, which plays an important role in promoting economic growth and industrial upgrading, promoting energy conservation and emission reduction, protecting the environment and improving ecological efficiency.

Guizhou, as a national experimental area of ecological civilization, Guian New Area is the first batch in China and the only national experimental area in southwest China to be allowed to carry out green financial reform and innovation. Firstly, the improvement of the level of ecological civilization construction plays a positive role in promoting the marketization and capitalization of ecological resources in Guizhou. Focusing on the three strategies of poverty

\footnotetext{
*Guizhou University of Finance and Economics, Huaxi Guiyang Guizhou 550025, China.

†Corresponding author: rim_007@163.com
} 
alleviation, big data and big ecology, Guizhou will focus on developing the "four-type" industries, which will bring huge investment opportunities and financial needs, provide support for Guizhou's ecological construction, and promote the realization of the "three orientations" in the new area. Finally, it will be conducive to fostering new momentum of economic development and providing loans for regional economic development. This paper uses intuitionistic fuzzy analytic hierarchy process (IFAHP) to comprehensively evaluate the level of ecological civilization construction in nine cities and municipalities of Guizhou and to provide development suggestions for improving the level of ecological civilization construction in Guizhou Province.

\section{An overview of domestic and foreign research}

With the improvement of environmental awareness, great progress has been made in the evaluation of the level of ecological civilization construction. Early scholar Zhao Fang (2010) ${ }^{[1]}$ decomposed the evaluation index of ecological civilization construction into four core areas: production mode, lifestyle, ecological protection and construction, social development, and set up several specific indicators, and constructed a threelevel, 27 single evaluation index structure from "target level-criterion level-index level". The evaluation index system of ecological civilization construction was established, and the progress rate analysis method was used to evaluate the construction of ecological civilization. In recent years, Zhang Huan et al. (2015) ${ }^{[2]}$ has established an evaluation index system of ecological civilization in mega-cities, which includes four aspects: the degree of ecological environment health, the intensity of resource and environment consumption, the efficiency of non-point source pollution control and the livability of residents, with a total of 20 indicators, and put forward measures to strengthen the construction of ecological civilization. Zheng Yanling et al. (2016) ${ }^{[3]}$ Taking Hebei Province as an example, this paper constructs a comprehensive evaluation index system of ecological civilization construction and regional economic development level, adopts the measurement model of ecological civilization construction and regional economic coordinated development, and puts forward that with the advancement of ecological civilization construction, the relationship between ecological civilization and economic development will enter into mutual complementarity. Good circulation. Cheng Jinhua et al. (2018) ${ }^{[4]}$ Taking 35 provincial capitals and sub-provincial cities in China and 7 small and medium-sized cities in Hubei Province as objects, the index system is constructed from four dimensions: land and space optimization, resource and energy utilization, ecological environment protection and governance, and ecological system construction. The index weight is given by the method of entropy weight. Empirical research finds that big cities are the main cities. Cities with a high index of ecological civilization often have the characteristics of balanced development of the economy and environment. There are few studies on the evaluation of Guizhou's ecological civilization construction, and more qualitative analysis is used to analyze the current situation of Guizhou's ecological civilization construction (Jiangchuan et al. ${ }^{[5]}$, 2014; Shipeixin ${ }^{[6]}, 2010$, etc.).

Van Laarhoven and Edrycz (1983) ${ }^{[7]}$ proposed for the first time to fuzzify the analytic hierarchy process (AHP). Buckley (1985) ${ }^{[8]}$ developed the fuzzy analytic hierarchy process (FAHP) on this basis. It is more complete and accurate to evaluate the target level indicators, which can reflect the uncertainty of the decision-makers in the evaluation of objective things. The subjectivity of experts is fuzzified, which is more objective and accurate than the analytic hierarchy process, but it can not accurately express the situation of abstention or hesitation, and the quantitative and qualitative indicators need to be aggregated by different methods. In order to solve this problem, an intuitionistic fuzzy analytic hierarchy process (IFAHP) based on the concept of fuzzy sets is proposed, which unifies the aggregation of qualitative and quantitative indicators. Intuitionistic Fuzzy Analytic Hierarchy Process (IFAHP) has also been widely used in the field of a comprehensive evaluation in China, and the effectiveness of this method has been proved ${ }^{[9]}$. For example, $\mathrm{Gu}$ Jing et al. (2015) ${ }^{[10]}$ used the intuitionistic fuzzy analytic hierarchy process to evaluate the performance of venture capital guiding fund. Compared with the traditional fuzzy analytic hierarchy process, it was found that this method has better performance in the evaluation accuracy. Zhang Shang-wai (2016) ${ }^{[11]}$ put forward that the intuitionistic fuzzy analytic hierarchy process (IFAHP) should be used to evaluate the operation status of power grid scientifically and reasonably and to rank the comprehensive evaluation 
values, which is of great significance for the prevention of major blackouts.

In view of this, on the basis of previous studies, this paper establishes an index system including four primary indicators: ecological economy, ecological environment, ecological livability and ecological culture, and then evaluates the level of ecological civilization construction in nine cities and municipalities of Guizhou Province by using intuitionistic fuzzy analytic hierarchy process.

\section{Establishment of an index system of Ecological Civilization Construction Level}

The selection of ecological civilization indicators plays an important role in accurately evaluating the level of ecological civilization construction. This paper follows the principles of comprehensiveness and representativeness, pertinence and comparability, orientation and foresight when constructing the index system. It emphasizes the sustainable development of nature, environment, human and society, and takes into account the carrying capacity of ecological environment, to promote the harmonious development of human and nature on the basis of improving social-ecological civilization. Reference [12], four first-level indicators and 23 second-level indicators were developed, such as Table 1.

The data sources of paper: China Regional Economic Statistics Yearbook, Guizhou Statistical Yearbook, Nine Prefecture, and City Statistical Yearbooks, Prefecture and City Water Resources Bulletin, Environment Bulletin and National Economic Development Bulletin. Among them, the per capita housing area of Anshun, southeastern Guizhou and southwestern Guizhou is estimated by the data of past years; the proportion of added value of cultural industry in GDP in Anshun, Zunyi, and Bijie, and the per capita green area of parks in southwestern Guizhou are estimated by the government's press announcement, and the sulfur dioxide emissions and industrial solid waste synthesis in southern Guizhou are estimated. Utilization ratio, the proportion of added value of cultural industry to GDP, average temperature and annual precipitation all come from the official website of the state government; the comprehensive utilization ratio of industrial solid waste in Tongren City, the per capita green space area of parks in southeastern Guizhou and southern Guizhou and the proportion of added value of
Table 1. Evaluation Index System of Ecological Civilization Construction Level in Guizhou.

\begin{tabular}{|c|c|}
\hline $\begin{array}{l}\text { First level } \\
\text { index }\end{array}$ & Two level index \\
\hline \multirow{6}{*}{$\begin{array}{l}\text { Eco } \\
\text { economy } \\
\text { A1 }\end{array}$} & Per capita gross domestic product(RMB) B1 \\
\hline & $\begin{array}{l}\text { The growth rate of the added value of the tertiary } \\
\text { industry as a proportion of GDP }(\%) \text { B2 }\end{array}$ \\
\hline & $\begin{array}{l}\text { Per capita growth rate of general public budget } \\
\text { income }(\%)\end{array}$ \\
\hline & $\begin{array}{l}\text { Energy Consumption per Unit GDP(Ton of Standard } \\
\text { Coal/10000 Yuan) }\end{array}$ \\
\hline & $\begin{array}{l}\text { Power consumption per unit GDP (kWh/10000 yuan) } \\
\text { B5 }\end{array}$ \\
\hline & $\begin{array}{l}\text { General Public Budget Expenditure - Energy } \\
\text { Conservation and Environmental Protection (RMB } \\
\begin{array}{ll}10,000) & \text { B6 }\end{array}\end{array}$ \\
\hline \multirow{6}{*}{$\begin{array}{l}\text { Ecological } \\
\text { environment } \\
\text { A2 }\end{array}$} & Forest cover $(\%)$ \\
\hline & $\begin{array}{l}\text { Excellent rate of urban ambient air quality (\%) } \\
\text { B8 }\end{array}$ \\
\hline & $\begin{array}{l}\text { Water quality of centralized drinking water sources } \\
\text { above county level (\%) B9 }\end{array}$ \\
\hline & $\begin{array}{l}\text { Increase rate of fertilizer application for agriculture } \\
(\%) \\
\begin{array}{ll}(\% 10 & \mathrm{B} 10\end{array}\end{array}$ \\
\hline & $\begin{array}{l}\text { Comprehensive } \text { Utilization Rate of Industrial Solid } \\
\text { Waste }(\%)\end{array}$ \\
\hline & $\begin{array}{l}\text { Total sulphur dioxide emissions }(10,000 \text { tons }) \\
\text { B12 }\end{array}$ \\
\hline \multirow{6}{*}{$\begin{array}{l}\text { Ecological } \\
\text { livability } \\
\text { A3 }\end{array}$} & $\begin{array}{l}\text { Per capita park green space area (square } \\
\text { metre/person) }\end{array}$ \\
\hline & $\begin{array}{l}\text { Harmless disposal rate of municipal solid waste (\%) } \\
\text { B14 }\end{array}$ \\
\hline & Average temperature ( $\mathrm{C}$ ) \\
\hline & Annual precipitation (mm) \\
\hline & Per capita highway mileage $(\mathrm{km})$ \\
\hline & $\begin{array}{l}\text { Per capita housing area in urban areas (square } \\
\text { meters) } \\
\text { B18 }\end{array}$ \\
\hline \multirow{5}{*}{$\begin{array}{l}\text { Ecological } \\
\text { culture } \\
\text { A4 }\end{array}$} & $\begin{array}{l}\text { General Public Budget Expenditure - Education } \\
\text { Services (RMB } 100 \text { million) B19 }\end{array}$ \\
\hline & $\begin{array}{l}\text { General Public Budget Expenditure - Culture, Sports } \\
\text { and Media (RMB } 100 \text { million) } \quad \text { B20 }\end{array}$ \\
\hline & $\begin{array}{l}\text { The proportion of the added value of the cultural } \\
\text { industry to GDP }(\%)\end{array}$ \\
\hline & $\begin{array}{l}\text { Students in Higher Education } \\
\text { B22 }\end{array}$ \\
\hline & $\begin{array}{l}\text { Students in Ordinary Secondary Schools (Persons) } \\
\text { B23 }\end{array}$ \\
\hline
\end{tabular}

cultural industry in GDP in southeastern Guizhou and southwestern Guizhou are estimated by the government's news bulletins.

\section{Models and Methods}

\subsection{Standardization of Data}

According to the attributes of the indicators, the indicators in this paper can be divided into benefit type, 
cost type, and medium type. Benefit-oriented indicators refer to the indicators with bigger values, while costoriented indicators refer to the indicators with smaller values. For benefit, cost and medium-sized indicators, the standardization methods ${ }^{[13]}$ are:

$$
\begin{aligned}
& z_{i j}=\frac{x_{j}{ }^{+}-x_{i j}}{x_{j}{ }^{+}-x_{j}{ }^{-}} ; z_{i j}=\frac{x_{i j}-x_{j}{ }^{-}}{x_{j}{ }^{+}-x_{j}{ }^{-}} ; \\
& z_{i j}=1-\frac{\left|x_{i j}-x_{j}{ }^{*}\right|}{\max \left|x_{i j}-x_{j}{ }^{*}\right|}, i=1,2, \ldots, n
\end{aligned}
$$

Among them, $i=1,2, \ldots, \mathrm{m}, \mathrm{m}$ is the number of evaluation objects; $j=1,2, \ldots, n, n$ is the number of attributes, $x_{j}^{+}=\max x_{i j}, x_{j}{ }^{-}=\min x_{i j}, x_{j}{ }^{*}$ is the best stable value of $\mathrm{j}$ index. After data standardization, the values measured by various attributes change from 0 to 1 .

\subsection{Comprehensive assessment Steps}

Atanassov further extends the theory of fuzzy sets proposed by Zadeh and defines intuitionistic fuzzy sets. Recently, intuitionistic fuzzy set theory has been widely used in decision-making field. The comprehensive assessment Steps of IFAHP are as follows:

The First Step: Determine the index system. This paper constructs the index system of ecological civilization construction from four perspectives of ecological economy, ecological environment, ecological livability, and ecological culture, as shown in Table 1.

The Second Step: Establish an intuitionistic fuzzy judgment matrix. This paper compares the importance of each factor of the same level index to a certain index of the upper level in two ways. Through expert scoring, an intuitionistic fuzzy judgment matrix $R=\left(R_{i j}\right)_{n \times n}$, $i, j$ is established to represent the rows and columns of the intuitionistic fuzzy judgment matrix, in which $R_{\mathrm{ij}}=\left(u_{i j}, v_{i j}\right)$ and $u_{i j}$ represent the membership degree, i.e., the degree of superiority of index $i$ to index $j, v_{i j}$ denotes non-membership, i.e. the degree of inferiority of index $i$ to index $j$, and $\pi_{i j}$ denotes hesitation, $\pi_{i j}=1-u_{i j}-v_{i j}$. The correspondence between qualitative evaluations and intuitionistic fuzzy numbers is shown in Table 2.

Step 3: Consistency test. The consistency test of the intuitive judgment matrix is carried out. If consistency is satisfied, jump to Step 5; otherwise, move to Step 4. Using the test formula
Table 2. Correspondence tables between qualitative evaluations and intuitionistic fuzzy numbers.

\begin{tabular}{|l|l|l|l|}
\hline $\begin{array}{c}\text { Qualitative } \\
\text { evaluation } \\
\text { language }\end{array}$ & \multicolumn{1}{|c|}{$\begin{array}{c}\text { Intuitionistic } \\
\text { fuzzy number }\end{array}$} & $\begin{array}{c}\text { Qualitative } \\
\text { evaluation } \\
\text { language }\end{array}$ & \multicolumn{1}{|c|}{$\begin{array}{c}\text { Intuitionistic } \\
\text { fuzzy number }\end{array}$} \\
\hline $\begin{array}{l}\text { Extremely } \\
\text { important }\end{array}$ & $(0.90,0.10,0.00)$ & $\begin{array}{l}\text { Less } \\
\text { important }\end{array}$ & $(0.4,0.45,0.15)$ \\
\hline $\begin{array}{l}\text { Very } \\
\text { important }\end{array}$ & $(0.80,0.15,0.05)$ & Unimportant & $(0.30,0.60,0.10)$ \\
\hline Important & $(0.70,0.20,0.10)$ & $\begin{array}{l}\text { Not } \\
\text { important }\end{array}$ & $(0.20,0.75,0.05)$ \\
\hline $\begin{array}{l}\text { More } \\
\text { important }\end{array}$ & $(0.60,0.25,0.15)$ & $\begin{array}{l}\text { Extremely } \\
\text { unimportant }\end{array}$ & $(0.10,0.90,0.00)$ \\
\hline $\begin{array}{l}\text { Equally } \\
\text { important }\end{array}$ & $(0.50,0.30,0.20)$ & \multicolumn{1}{|c}{-} & - \\
\hline
\end{tabular}

$d(\bar{R}, R)=\frac{1}{2(n-1)(n-2)} \sum_{i=1}^{n} \sum_{j=1}^{n}\left(\left|\overline{u_{i j}}-u_{i j}\right|+\left|\overline{v_{i j}}-v_{i j}\right|+\left|\overline{\pi_{i j}}-\Pi_{\mathrm{ij}}\right|\right)$

$\mathrm{R}$ is an intuitionistic fuzzy judgment matrix and an intuitionistic fuzzy consistency judgment matrix, $\bar{R}=\left(\overline{R_{i j}}\right)_{n \times n}$.

(1)When $\mathrm{j}>\mathrm{i}+1, \bar{R}=\left(\overline{r_{i j}}\right)=\left(\overline{u_{i j}}, \overline{v_{i j}}\right)$;

$$
\begin{aligned}
& \overline{u_{i j}}=\frac{\sqrt[j-i-1]{\prod_{t=i+1}^{j-1} u_{i t} u_{t j}}}{\sqrt[j-i-1]{\prod_{t=i+1}^{j-1} u_{i t} u_{t j}}+\sqrt[j-i-1]{\prod_{t=i+1}^{j-1}\left(1-u_{i t}\right)\left(1-u_{t j}\right)}}, j>i+1 \\
& \overline{v_{i j}}=\frac{\sqrt[j-i-1]{\prod_{t=i+1}^{j-1} v_{i t} v_{i j}}}{\sqrt[j-i-1]{\prod_{t=i+1}^{j-1} v_{i t} v_{j j}}+\sqrt[j-i-1]{\prod_{t=i+1}^{j-1}\left(1-v_{i t}\right)\left(1-v_{t j}\right)}}, j>i+1
\end{aligned}
$$

(2)When $\mathrm{j}=\mathrm{i}+1$, order $\overline{r_{i j}}=r_{i j}$;

(3)When $\mathrm{j}<\mathrm{i}+1$, order $\overline{r_{i j}}=\left(\overline{v_{i j}}, \overline{u_{i j}}\right)$.

The intuitionistic fuzzy consistency judgment matrix $R=\left(R_{i j}\right)_{n \times n}$ is substituted into the test formula for consistency test. If $d(\bar{R}, R)<0.1$ it passes the consistency test, otherwise it fails.

Step 4: Revise the intuitive judgment matrix which does not satisfy the consistency test. If it fails to pass the consistency test, it is necessary to set the parameter $\sigma$ for iteration, where $\sigma \in[0,1]$, until it passes the consistency test, the following formula is used:

$$
\begin{aligned}
\tilde{u_{i j}} & =\frac{u_{i j}{ }^{(1-\sigma)} u_{i j}{ }^{(\sigma)}}{u_{i j}{ }^{(1-\sigma)}{\overline{u_{i j}}}^{(\sigma)}+\left(1-u_{i j}\right)^{(1-\sigma)}\left(1-\overline{u_{i j}}\right)^{(\sigma)}} \\
\tilde{v_{i j}} & =\frac{v_{i j}{ }^{(1-\sigma)} \bar{v}_{i j}{ }^{(\sigma)}}{v_{i j}{ }^{(1-\sigma)}{\overline{v_{i j}}}^{(\sigma)}+\left(1-v_{i j}\right)^{(1-\sigma)}\left(1-\overline{v_{i j}}\right)^{(\sigma)}}, i, j=1,2, \ldots, n
\end{aligned}
$$

Step 5: Calculate the weight. According to the 
intuitionistic fuzzy consistency judgment matrix, the weight is calculated.

$$
\omega i=\left(\frac{\sum_{j=1}^{n} u i j}{\sum_{i=1}^{n} \sum_{j=1}^{n}(1-v i j)}, 1-\frac{\sum_{j=1}^{n}(1-u i j)}{\sum_{i=1}^{n} \sum_{j=1}^{n} v i j}\right), i=1,2, \ldots, n
$$

Step 6: Using intuitionistic fuzzy number operator to calculate the combined weights of each level of indicators on ecological civilization. $\mathrm{W}_{\mathrm{A}}$ is the weight of the first level index; $W_{B}$ is the weight of the second level index.

$$
\begin{aligned}
& \alpha 1 \otimes \alpha 2=(u \alpha 1 \bullet u \alpha 2, v \alpha 1+v \alpha 2-v \alpha 1 \bullet v \alpha 2) \\
& \alpha 1 \oplus \alpha 2=(u \alpha 1+u \alpha 2-u \alpha 1 \bullet u \alpha 2, v \alpha 1 \bullet v \alpha 2) \\
& W j=\underset{j=1}{n_{1}}(w B i j \otimes w A j)
\end{aligned}
$$

Step 7: Substitute standardized index values into $F_{\mathrm{i}}=\bigoplus_{j=1}^{n}\left(Z_{i j} \otimes W_{j}\right)$. The comprehensive evaluation value is obtained, and then the ranking of the construction level of ecological civilization in nine cities and municipalities is obtained. The bigger the ranking, the higher the construction level of ecological civilization.

\section{Empirical Analysis}

According to Step 2, the intuitionistic fuzzy judgment matrix is established. According to the experts' opinions, in order to evaluate the level of ecological civilization construction, the importance of the first-level indicators from big to small is the ecological environment, ecological livability, ecological culture, and ecological economy. Taking the ecological environment as an example, this paper introduces the process of empirical analysis in detail. Under this first-level index, according to the importance degree of the second-level index, the good rate of urban environmental air quality, forest coverage, total $\mathrm{SO} 2$ emission, comprehensive utilization rate of industrial solid waste, water quality standard rate of centralized drinking water sources above county level and the growth rate of agricultural chemical fertilizer application rate are respectively.

According to the expert opinions, the former is more important than the forest coverage, and the corresponding intuitionistic fuzzy number is $(0.6,0.25)$; the former is very important, and the intuitionistic fuzzy number is $(0.8,0.15)$; the former is important, and the intuitionistic fuzzy number is $(0.8,0.15)$; the comprehensive utilization ratio of forest coverage and industrial solid waste is important, the former is important, and the intuitionistic fuzzy number is $(0.7$, 0.2 ). By analogy, experts' opinions corresponded to intuitionistic fuzzy numbers, and the intuitionistic fuzzy judgment matrix is established as shown in Table 3. The calculation method and process of the other matrices are the same.

Set up the iteration parameters, make $\sigma=1 / 4$, and use Step 4 to calculate $(\tilde{u}, \tilde{v})$, as shown in Table 4 . The consistency test was carried out again, $\mathrm{d}=0.048<0.1$. Through the consistency test, the intuitionistic fuzzy consistency judgment matrix was established as shown in the table. The calculation method and process of the other matrices are the same.

According to Step 6, the combination weight is calculated. The combined weights of six secondary indicators under ecological environment are $(0.058$, $0.895),(0.070,0.883),(0.025,0.946),(0.038,0.930)$, $(0.032,0.935)$ and $(0.046,0.913)$.

It is extended to the other four matrices. According to the first Step to the fourth Step of calculation, after establishing the intuitionistic fuzzy judgment matrix in the form of expert scoring, the consistency test is carried out. It is found that the four intuitionistic fuzzy judgment matrices do not satisfy the consistency test. The four matrices $d(\bar{R}, R)$ are $0.1333,0.186,0.153$ and 0.11 respectively, which are greater than 0.1 and do not satisfy the consistency test. Therefore, setting parameters to $\sigma=1 / 4$, adjusting intuitionistic fuzzy judgment matrix, and then conducting consistency test, $d(\bar{R}, R)$ are $0.035,0.049,0.038$ and 0.046 respectively, which are less than 0.1 , satisfying the consistency test. The weight of the index is calculated from the fifth and sixth Steps as shown in Table 5.

According to the three cases of $\mathrm{i}$ and $\mathrm{j}$ in Step 3, and are calculated respectively, and the intuitionistic fuzzy consistency judgment matrix is established, as shown in Table 6 . The calculation method and process of the other matrices are the same.

The consistency test was carried out by using the test formula, $\mathrm{d}=0.0208>00.1$, which did not pass the consistency test. Therefore, it can be said that the above table is not an intuitionistic fuzzy consistency judgment matrix. The calculation method and process of the other matrices are the same.

The Step 7 is used to calculate the comprehensive evaluation values of nine prefectures and cities, and the 
Table 3. Intuitionistic Fuzzy Judgment Matrix.

\begin{tabular}{ccccccc}
\hline & B7 & B8 & B9 & B10 & B11 & B12 \\
\hline B7 & $(0.5,0.5)$ & $(0.25,0.6)$ & $(0.8,0.15)$ & $(0.8,0.15)$ & $(0.7,0.2)$ & $(0.6,0.25)$ \\
B8 & $(0.6,0.25)$ & $(0.5,0.5)$ & $(0.8,0.15)$ & $(0.9,0.1)$ & $(0.8,0.15)$ & $(0.7,0.2)$ \\
B9 & $(0.15,0.8)$ & $(0.15,0.8)$ & $(0.5,0.5)$ & $(0.25,0.6)$ & $(0.25,0.6)$ & $(0.2,0.7)$
\end{tabular}

Table 4. Intuitionistic Fuzzy Consistency Judgment Matrix.

\begin{tabular}{ccccccc}
\hline & B7 & B8 & B9 & B10 & B11 & B12 \\
\hline B7 & $(0.5,0.5)$ & $(0.25,0.6)$ & $(0.57,0.2)$ & $(0.67,0.17)$ & $(0.72,0.13)$ & $(0.49,0.28)$ \\
B8 & $(0.6,0.25)$ & $(0.5,0.5)$ & $(0.8,0.15)$ & $(0.57,0.2)$ & $(0.8,0.08)$ & $(0.62,0.23)$ \\
B9 & $(0.2,0.57)$ & $(0.15,0.8)$ & $(0.5,0.5)$ & $(0.25,0.6)$ & $(0.44,0.27)$ & $(0.1,0.73)$ \\
B10 & $(0.17,0.67)$ & $(0.2,0.57)$ & $(0.6,0.25)$ & $(0.5,0.5)$ & $(0.7,0.2)$ & $(0.61,0.17)$ \\
B11 & $(0.13,0.72)$ & $(0.08,0.8)$ & $(0.27,0.44)$ & $(0.2,0.7)$ & $(0.5,0.5)$ & $(0.4,0.45)$ \\
B12 & $(0.28,0.49)$ & $(0.23,0.62)$ & $(0.73,0.1)$ & $(0.17,0.61)$ & $(0.45,0.4)$ & $(0.5,0.5)$
\end{tabular}

Table 5. Intuitionistic Fuzzy Consistency Judgment Matrix.

\begin{tabular}{ccccccc}
\hline & B7 & B8 & B9 & B10 & B11 & B12 \\
\hline B7 & $(0.5,0.5)$ & $(0.25,0.6)$ & $(0.75,0.16)$ & $(0.77,0.15)$ & $(0.71,0 ., 18)$ & $(0.57,0.26)$ \\
B8 & $(0.6,0.25)$ & $(0.5,0.5)$ & $(0.8,0.15)$ & $(0.85,0.12)$ & $(0.80,0.13)$ & $(0.68,0.21)$ \\
B9 & $(0.16,0.75)$ & $(0.15,0.8)$ & $(0.5,0.5)$ & $(0.25,0.6)$ & $(0.29,0.51)$ & $(0.17,0.71)$ \\
B10 & $(0.15,0.77)$ & $(0.12,0.85)$ & $(0.6,0.25)$ & $(0.5,0.5)$ & $(0.7,0.2)$ & $(0.23,0.66)$ \\
B11 & $(0.18,0.71)$ & $(0.13,0.80)$ & $(0.51,0.29)$ & $(0.2,0.7)$ & $(0.5,0.5)$ & $(0.4,0.45)$ \\
B12 & $(0.26,0.57)$ & $(0.21,0.68)$ & $(0.71,0.17)$ & $(0.66,0.23)$ & $(0.45,0.4)$ & $(0.5,0.5)$
\end{tabular}

Table 6. Total Weight Tables of Indicators.

\begin{tabular}{|c|c|c|c|c|c|}
\hline $\begin{array}{c}\text { First level index } \\
\text { weight }\end{array}$ & $\begin{array}{c}\text { Two level index } \\
\text { weight }\end{array}$ & Total weight & $\begin{array}{c}\text { First level index } \\
\text { weight }\end{array}$ & $\begin{array}{c}\text { Two level index } \\
\text { weight }\end{array}$ & Total weight \\
\hline \multirow{6}{*}{$(0.137,0.785)$} & $(0.092,0.832)$ & $(0.013,0.964)$ & \multirow{6}{*}{$(0.237,0.676)$} & $(0.137,0.795)$ & $(0.033,0.934)$ \\
\hline & $(0.144,0.772)$ & $(0.020,0.951)$ & & $(0.137,0.805)$ & $(0.032,0.937)$ \\
\hline & $(0.081,0.868)$ & $(0.011,0.972)$ & & $(0.229,0.712)$ & $(0.054,0.907)$ \\
\hline & $(0.187,0.729)$ & $(0.026,0.942)$ & & $(0.186,0.754)$ & $(0.044,0.920)$ \\
\hline & $(0.105,0.818)$ & $(0.014,0.961)$ & & $(0.040,0.891)$ & $(0.010,0.965)$ \\
\hline & $(0.185,0.722)$ & $(0.025,0.940)$ & & $(0.088,0.867)$ & $(0.021,0.957)$ \\
\hline \multirow{6}{*}{$(0.324,0.587)$} & $(0.180,0.746)$ & $(0.058,0.895)$ & \multirow{6}{*}{$(0.149,0.772)$} & $(0.142,0.754)$ & $(0.021,0.944)$ \\
\hline & $(0.215,0.716)$ & $(0.070,0.883)$ & & $(0.159,0.740)$ & $(0.024,0.941)$ \\
\hline & $(0.077,0.869)$ & $(0.025,0.946)$ & & $(0.222,0.662)$ & $(0.033,0.923)$ \\
\hline & $(0.117,0.830)$ & $(0.038,0.930)$ & & $(0.141,0.747)$ & $(0.021,0.942)$ \\
\hline & $(0.098,0.844)$ & $(0.032,0.935)$ & & $(0.105,0.797)$ & $(0.016,0.954)$ \\
\hline & $(0.142,0.788)$ & $(0.046,0.913)$ & & & \\
\hline
\end{tabular}


ranking results are shown in Table 7, where the comprehensive evaluation value of southeastern Guizhou is 12.72 , with the highest score, followed by Guiyang, southern Guizhou, southwestern Guizhou, Tongren, and Zunyi, with 11.94, 11.88, 11.42, 10.97 and 10.72 respectively. Bijie, Anshun and Liupanshui scored lower, 9.72, 9.55 and 7.81 respectively. The construction level of ecological civilization in nine cities and municipalities is relatively high, but the development level is unbalanced.

Table 7. Ranking table of comprehensive evaluation results.

\begin{tabular}{|c|c|c|}
\hline Region & $\begin{array}{c}\text { Comprehensive evaluation } \\
\text { value }\end{array}$ & Sort \\
\hline Qiandongnan & 12.72 & 1 \\
\hline Guiyang & 11.94 & 3 \\
\hline Qiannan & 11.88 & 4 \\
\hline Qianxinan & 11.42 & 5 \\
\hline Tongren & 10.97 & 6 \\
\hline Zunyi & 10.72 & 8 \\
\hline Bijie & 9.72 & 9 \\
\hline Anshun & 9.55 & \\
\hline Liupanshui & 7.81 & 2 \\
\hline
\end{tabular}

\section{Conclusion}

This paper applies the intuitionistic fuzzy analytic hierarchy process (IFAHP) to evaluate the level of ecological civilization construction in Guizhou Province and establishes an index system including four firstlevel indicators of the ecological economy, ecological environment, ecological livability and ecological culture, and 23 second-level indicators. The index weights are expressed by the intuitionistic fuzzy numbers, and then the scores are calculated and compared. However, limited by the statistical data of each prefecture and city, the representative of individual indicators is not strong.

The empirical study of this paper shows that the level of ecological civilization construction in Guizhou Province is relatively high, but the level of each prefecture is quite different. Therefore, it is necessary for the governments, environmental protection bureaus and water conservancy bureaus of various prefectures and municipalities in Guizhou Province to take measures to further improve the ecological quality. For example, Guizhou Province should make full use of ecological resources, promote the marketization and capitalization of ecological resources in Guizhou Province, and respond to the national strategy to achieve green development, improve the efficiency of clean energy use, improve citizens'awareness of environmental protection, and increase the penalties for excessive pollutants discharged by industrial enterprises.

\section{Acknowledgments}

Fund Projects: Regional Project of National Natural Science Foundation of China (71861003); The Second Batch Projects of Basic Research Program (Soft Science Category) in Guizhou Province in 2017 (Foundation of Guizhou-Science Cooperation [2017] 1516-1).

\section{References}

[1] Zhao Fang. Establishment and Empirical Study of evaluation index system for ecological civilization construction [D]. Chinese Academy of Forestry Sciences, 2010.

[2] Zhang Huan, Cheng Jinhua, Feng Yin, Chen Dan, Ni Lin, Sun Han. Evaluation index system and its application for the construction of ecological civilization in mega-cities: a case study of Wuhan [J]. Journal of Ecology, 2015, 35 (02): 547-556.

[3] Zheng Yanling, Gao Jianshan, Han Fubin. Study on the Performance Evaluation of the Harmonious Development of Ecological Civilization and Regional Economy: A Case Study of Hebei Province [J]. Eco-economy, 2016, 32(12): 198-203.

[4] Cheng Jinhua, Peng Xinjie, Feng Yin. Evaluation of Chinese Urban Ecological Civilization [J]. Journal of China University of Geosciences (Social Science Edition), 2018, 18 (02): 102-113.

[5] Jiangchuan, Wang Zhiming, Huang Wen Hu. The present situation and Countermeasures of ecological civilization construction in Guizhou province [J]. China environmental monitoring, 2014, 30 (03): 13-17.

[6] Shi Ba Xin. Some thoughts on the construction of ecological civilization in Guizhou [J]. Journal of Guizhou Teachers College, 2010, 26 (02): 8-11.

[7] Van Laarhoven PLM Pedrycz W.A fuzzy extension of Saaty's priority theory [J].Fuzzy Sets and Systems, 1983, 11(1): 229-241.

[8] Buckley J J. Fuzzy hierarchical analysis [J].Fuzzy Sets and Systems, 1985, 3(17): 233-247.

[9] Gao Hongyun, Wang Chao, Haminghu. Intuitionistic Fuzzy Analytic Hierarchy Process [J]. Journal of Hebei University of Engineering (Natural Science Edition), 2011, 28 (04): 101-105.

[10] Zhang Shang, Wang Tao, Gu Xueping. A comprehensive evaluation of power network operation status based on intuitionistic fuzzy analytic hierarchy process [J]. Power system automation, 2016, 40 (04): 4149. 
[11] Gu Jing, Ren Bijia and Xu Zeshui. Research on the Performance Evaluation Method of Venture Capital Guidance Fund Based on Intuitionistic Fuzzy Analytic Hierarchy Process [J]. China Management Science, 2015, 23 (09): 124-131.

[12] Lin Zhen, Shuangzhimin. A comparative study on the evaluation index system of eco-civilization construction in provincial capitals: Taking Guiyang, Hangzhou, and Nanjing as examples [J]. Journal of Beijing University of Aeronautics and Astronautics (Social Sciences Edition), 2014, 27 (05): 22-28.

[13] Mu Zhang, Zongfang Zhou.A Credit Rating Model for Enterprises Based on Projection Pursuit and K-Means Clustering Algorithm[J].JRACR, 2012(2): 131-138. 